\title{
Numerical Modelling and Mitigation Technique of Welding Distortion for Fillet Welding of Aluminum Plate
}

\author{
M. Tsunori ${ }^{1, a^{*}}$, M. Mouri ${ }^{2, b}$, S. Saso ${ }^{2, c}$ and H. Kusumoto ${ }^{3, d}$ \\ ${ }^{1} \mathrm{IHI}$, Structure and Strength Department, Research Laboratory, Yokohama, Japan \\ ${ }_{2}^{2} \mathrm{HI}$, Welding Technology Department, Production Engineering Center, Yokohama, Japan \\ ${ }^{3}$ Japan Marine United, Gas Project Department, Offshore and Engineering Division, Tokyo, \\ Japan \\ amitsuyoshi_tsunori@ihi.co.jp, ${ }^{b}$ masashi_mouri@ihi.co.jp, \\ cshun_sasou@ihi.co.jp, dkusumoto-hiroki@jmuc.co.jp
} Keywords: Weld Distortion, Residual Stress, In-Process Heating, Finite Element
Method

\begin{abstract}
In marine and offshore industries, aluminium welding processes are often used especially for floating LNG (Liquefied Natural Gas) production, storage and LNG fuelled vessels. Welding distortions of aluminium plates are known to be larger than that of steel, so it is desired to mitigate the distortion. Also, numerical models of welding distortion prior to a manufacturing of components are expected in order to improve products. Finite element models of welding residual stresses and distortions on aluminium plates by using the commercial finite element code ABAQUS were developed in this study. A mixed material hardening model was employed in order to simulate aluminium material behaviours. In addition, a mitigation technique of distortions by in-process additional heating of plate bottom side was investigated by using the developed numerical models. The finite element models were validated by experiments which distortions and temperature histories of MIG fillet welding were measured. Experiments of in-process additional heating of plate bottom side were also conducted and results were compared with the simulation. The simulations and the experiments showed that the mitigation technique proposed in this study was able to achieve a reduction of distortions for aluminium fillet welding.
\end{abstract}

\section{Introduction}

A5083-O aluminium alloy is often used for marine and offshore industries especially for floating LNG (Liquefied Natural Gas) production, storage and LNG fuelled vessels since it has better strength to weight ratio and corrosion resistances compared with steel. Welding distortion of aluminium alloy is larger than that of steel and more difficult to remedy after the weld. Therefore, a prediction of distortions prior to manufacturing processes and mitigation techniques are desired.

A development of finite element models for welding distortion was originated from 1970's [1] and many researchers contributed the development [2,3]. Throughout the studies of the prediction of weld distortion, prediction accuracies were dependent on weld heat source models used in finite element models. Effect of material constitutive model was studied by the round robin project [4]. This project investigated experimental and numerical techniques for characterisation of residual stresses on a single bead on plate problem. This research concluded that predicted residual stresses and distortion are sensitive to material constitutive models.

Demands of mitigation techniques of welding distortion are increased. Several mitigation methods, which are mechanical constraint, pre-heating, in-process cooling and in-process heating $[5,6,7,8]$, have been proposed, then it is important to choose an appropriate method for individual components. The mechanical constraint technique is the simplest method, but this technique requires 
a huge mechanical load coping with a thermal load due to weld for large components. In case of aluminium components, it is difficult to apply thermal heating processes after the weld to correct the weld distortion because of a difficulty of controlling temperature distributions by the large thermal conductivity of aluminium alloy. Therefore, in-process technique is more desirable. In-process method of MIG welding of thin aluminium plates was studied and TIG heating ahead of MIG welding was effective to reduce weld distortions [6]. Therefore, the in-process heating technique is applicable but a heating condition should be optimised for different case because temperature field is sensitive with welding condition and plate thickness.

In this study, finite element models of the welding distortion and in-process additional heating of bottom side of aluminium plates were developed. Additional heating conditions to minimise weld distortions were optimsed by using the numerical models. Experiments of additional heating processes were conducted and a reduction of the weld distortion was achieved.

\section{Experimental and numerical procedure}

Experimental procedure. Dimensions of A5083-O aluminium plates used in the experiment are shown in Figure 1. Chemical compositions and mechanical properties of A5083-O aluminium are listed in Table 1 and Table 2. The web plate was fillet welded to the skin plate by MIG welding with A5183-WY filler metal. Both sides of the web plate were simultaneously fillet welded. During the welding process, the skin plate was rested on a jig and there was no clamp in order to avoid mechanical constraining effect. A heat source model of the TIG heating was investigated by using a thick plate, which is shown in Figure 1. Thick plate was used to reduce unexpected distortions by the TIG heating. The MIG welding and the TIG heating conditions are shown in Table 3. Weld distortion mitigation technique introducing in this study is schematically illustrated in Figure 2. The TIG torch was selected for the additional heat source. The heat input and velocity of the MIG welding and the TIG heating were kept constant during the welding. Weaving technique was used for the TIG torch in order to broaden heating area. A distance between the MIG welding torch and the TIG torch was selected as a parameter to be optimsed. In situ temperature measurements by thermocouples were made during the welding and heating experiments. The locations of thermocouples are shown in Figure 1. After the fillet welding experiments, plate distortion was measured by a photogrammetric measurement system. The photogrammetric measurement was done by taking digital photos of specimens with attached targets from various directions and the photos were processed to obtain three dimensional coordinates of the targets. The angular distortions at the plate edge were calculated from the results of the photogrammetric measurement.

Finite element model. The commercial finite element code ABAQUS [9] was selected to develop numerical models. A symmetry boundary condition was considered at the middle of the web plate so only half of the specimens were modelled. Dense and graded mesh distributions close to the fillet weld and additional heating area was made in the models. Effect of deformation field to thermal field was assumed to be small and neglectable therefore a sequentially coupled thermal-stress analysis was performed. The transient temperature field previously calculated by the heat transfer analysis was used as thermal load within the mechanical analysis.

A simple moving heat source model that assumes uniform distribution in the fillet weld metal area was utilized in the analysis. The ABAQUS user subroutine called DFLUX was implemented in order to model this moving heat source model. Efficiencies of the MIG welding and the TIG heating were determined by comparing with the result of temperature measurements of several cases in this research and listed in Table 3. It is necessary to take into account temperature dependent material properties [6]. They were measured up to $550{ }^{\circ} \mathrm{C}$ to improve an accuracy of the finite element models in this study. A heat transfer coefficient at the ambient temperature was determined as $10 \mathrm{~W} / \mathrm{m}^{2} /{ }^{\circ} \mathrm{C}$ and an emissivity used in the simulation was 0.4 , respectively.

A choice of material constitutive model is one of the most important aspects of mechanical analysis. Isotropic hardening rule is the simplest model and often used in weld simulations although it is well known that it gives overestimated residual stresses. A mixed isotropic and kinematic 
hardening model is more accurate if the model is fitted to both a monotonic response and a cyclic response. In the present study, mixed hardening rule called Chaboche model implemented in ABAQUS was employed in order to overcome the shortcomings of isotropic hardening rule. The Chaboche model in ABAQUS is represented by the following equations.

$$
\begin{aligned}
& f(\boldsymbol{\sigma}-\boldsymbol{\alpha})=\sqrt{\frac{3}{2}\left(\mathbf{S}-\boldsymbol{\alpha}^{d e v}\right):\left(\mathbf{S}-\boldsymbol{\alpha}^{d e v}\right)}=\sigma^{0} \\
& \dot{\boldsymbol{\alpha}}=\sum_{k}\left[C_{k} \frac{1}{\sigma^{0}}(\boldsymbol{\sigma}-\boldsymbol{\alpha}) \dot{\bar{\varepsilon}}^{p l}-\gamma_{k} \dot{\boldsymbol{\alpha}}^{p l}\right] \\
& \sigma^{0}=\left.\sigma\right|_{0}+Q_{\infty}\left(1-e^{-b \bar{\varepsilon}^{p l}}\right)
\end{aligned}
$$

where $\boldsymbol{\sigma}$ is the stress tensor, $\boldsymbol{\alpha}$ is the back stress tensor, $f(\boldsymbol{\sigma}-\boldsymbol{\alpha})$ is the equivalent von Mises stress, $\sigma^{0}$ is the size of the yield surface, $\mathbf{S}$ is the deviatoric stress tensor, $\boldsymbol{\alpha}^{\text {dev }}$ is the deviatoric part of the back stress tensor, $\bar{\varepsilon}^{p l}$ is the equivalent plastic strain, $\dot{\bar{\varepsilon}}^{p l}$ is the equivalent plastic strain rate, $\left.\sigma\right|_{0}$ is the yield stress at zero plastic strain, and $C_{k}, \gamma_{k}, Q_{\infty}$ and $b$ are material parameters to be calibrated. Cyclic loading tests were carried out in addition to standard tensile tests in order to identify the parameters. One representative result, whose temperature was at room temperature, was shown in Figure 3. The result of the mixed hardening model shows better agreement with experimental results than that of the isotropic hardening model for the case of the cyclic test.
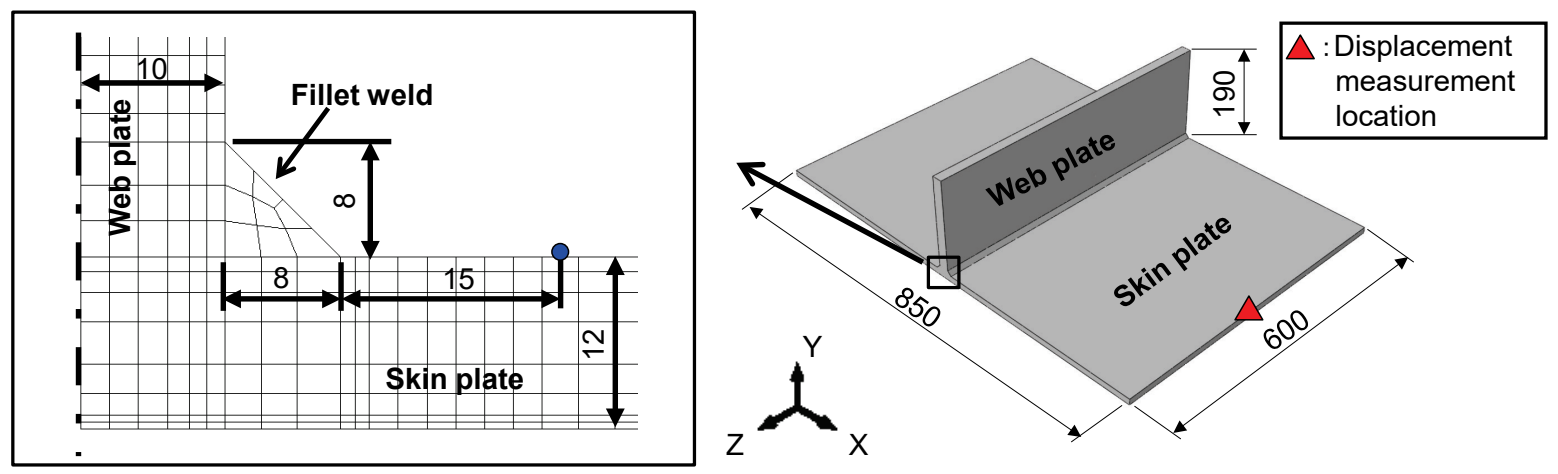

(a) Fillet welded aluminium plate
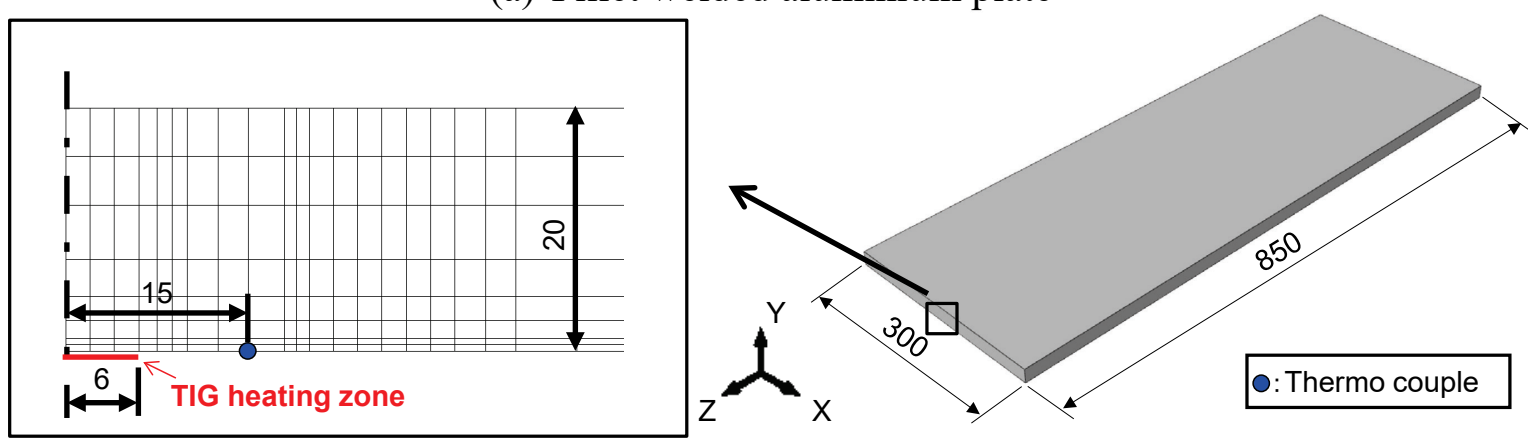

(b) Aluminium plate of TIG heating

Figure 1. Schimatic and finite element models of the specimens with dimensions and thermocouple position 
Table 1. Chemical composition of A5083-O plate

\begin{tabular}{cccccccccc}
\hline \hline Element & $\mathrm{Si}$ & $\mathrm{Fe}$ & $\mathrm{Cu}$ & $\mathrm{Mn}$ & $\mathrm{Mg}$ & $\mathrm{Cr}$ & $\mathrm{Zn}$ & $\mathrm{Ti}$ & $\mathrm{Al}$ \\
\hline Weight $(\%)$ & 0.09 & 0.24 & 0.04 & 0.6 & 4.5 & 0.08 & 0.01 & 0.01 & Bal. \\
\hline \hline
\end{tabular}

Table 2. Mechanical properties of A5083-O plate conditions

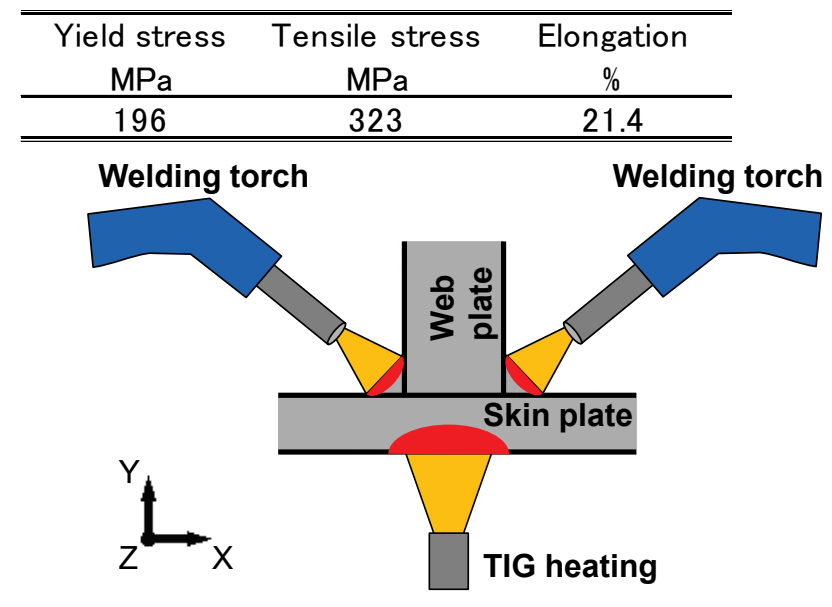

Table 3. MIG welding and TIG heating

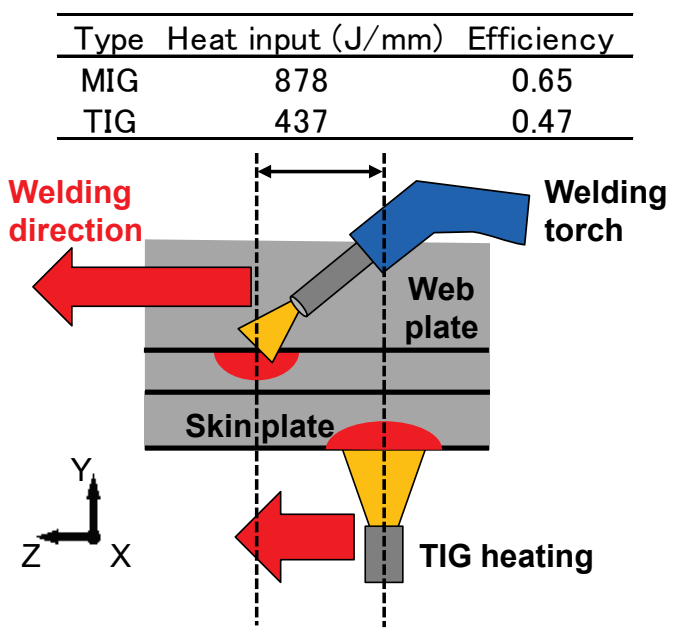

Figure 2. Schematic illustration of in-process additional heating technique

(a)

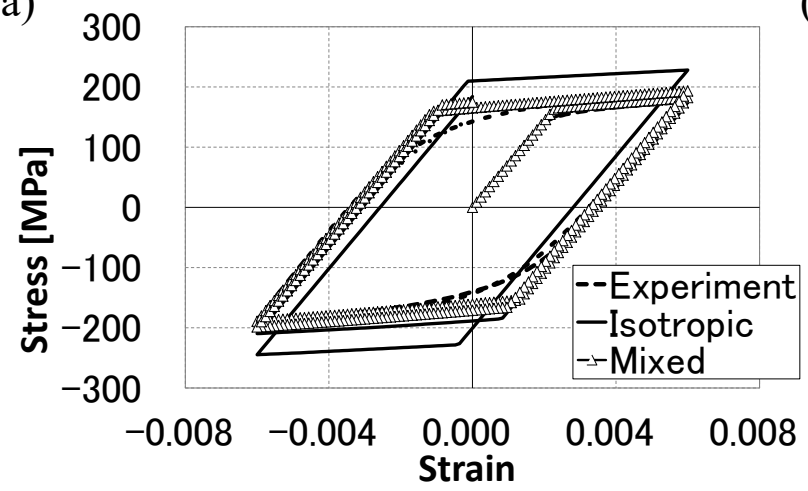

(b)

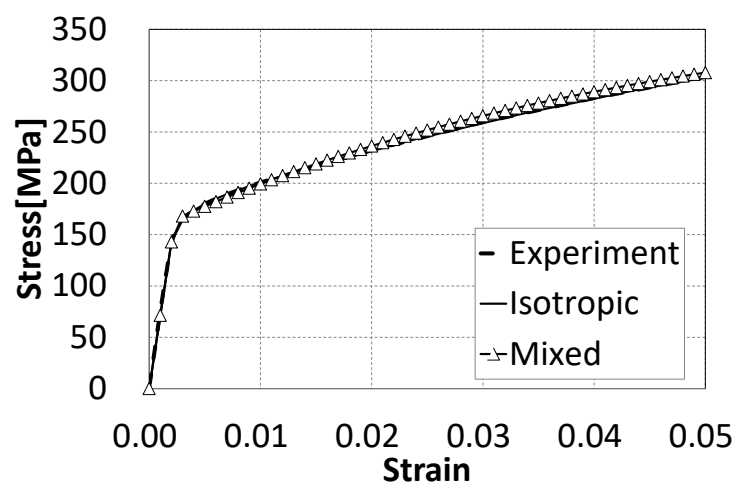

Figure 3. Stress-strain relationship used in finite element model compared with experiments. (a) Stress-strain relationship by cyclic loading (b) Stress-strain relationship by tensile test

\section{Validation ofthe finite element models}

Results of numerical models and thermocouple measurements of the MIG welding and the TIG heating are shown in Figure 4. As seen from the Figure 4 (a), a good agreement of temperature histories was obtained for the MIG welding. On the other hand, a discrepancy of the maximum temperature of the TIG heating was observed. One reason was that the numerical model did not take into account the weaving process of the TIG heating and it was affected to the results. Temperature histories and cross sections of the welded plate with the TIG additional heating were compared and results are shown in Figure 5. The TIG torch was placed $-40 \mathrm{~mm}$ behind the MIG torch. A good agreement was observed for the temperature history. Larger melt pool was observed by the finite element analysis in comparison with the experiment. The difference was also considered by absence of the weaving effect of the TIG torch in the finite element model.

The out of plane displacement of the plate edge, which is indicated in Figure 1, obtained by the finite element model was listed in Table 4. There was a good agreement between the numerical model and the experiment for the MIG welding. The reduction rate of distortion by the additional 
heating was approximately $62 \%$ in the experiment. Predicted reduction rate was larger than the experiment. This was due to the predicted larger melting pool in the numerical model.
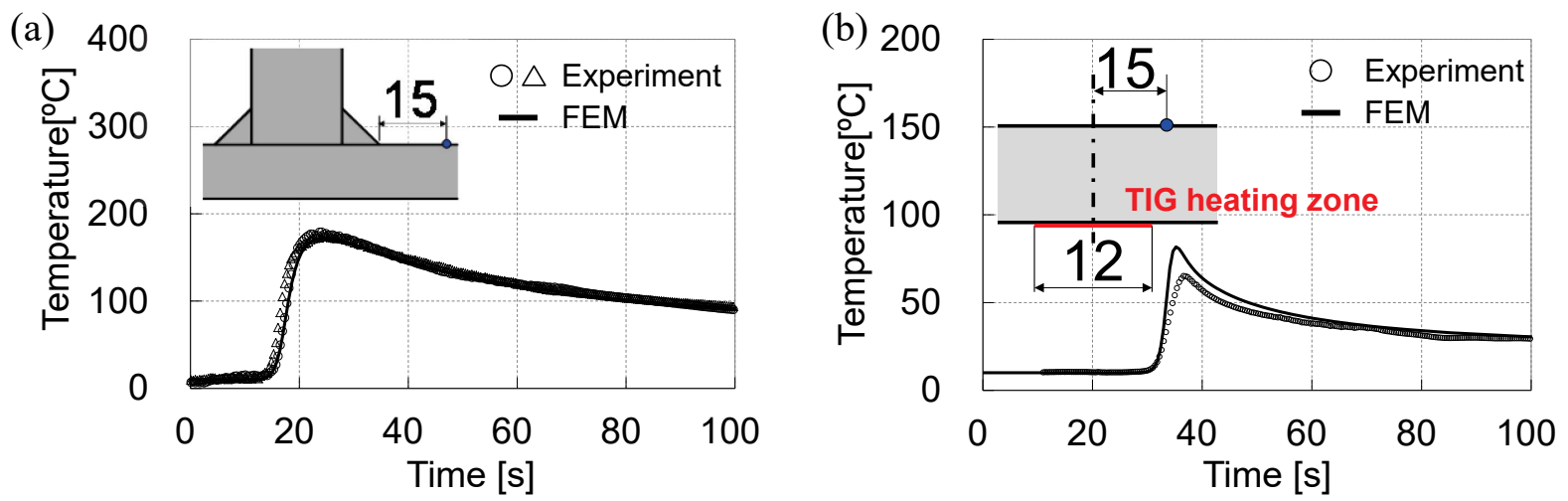

Figure 4. Comparison of predicted and measured temperature profiles at thermocouple locations. (a) MIG welding (b) TIG heating

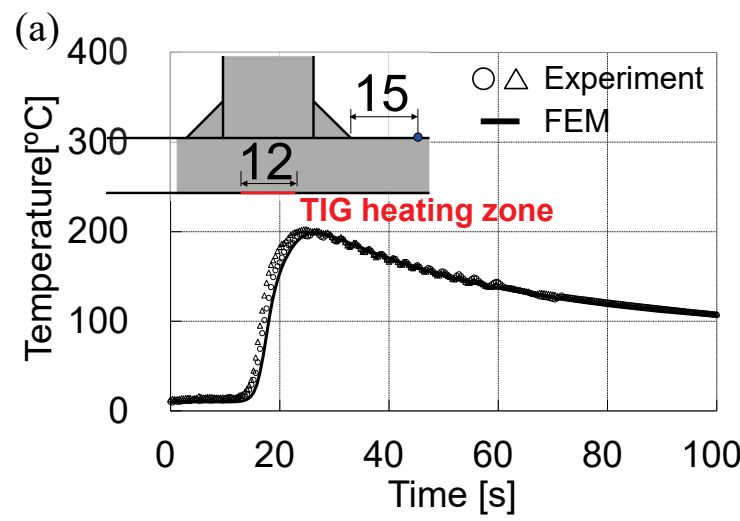

(b)

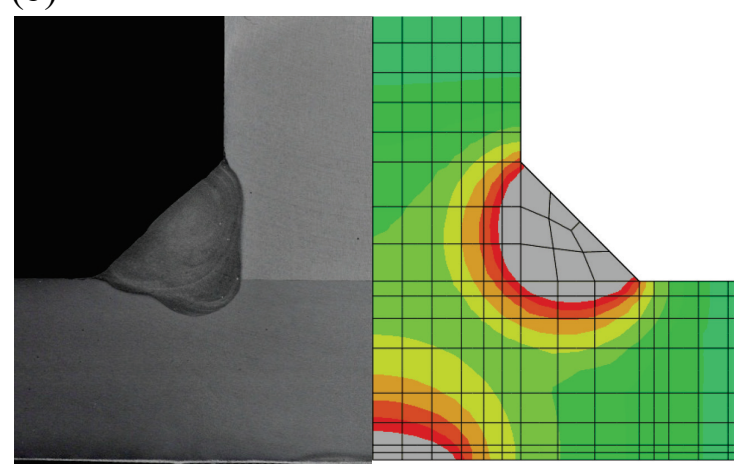

Figure 5. Comparison of experiment and finite element model of additional TIG heating (-40 $\mathrm{mm}$ ). Temperature history (b) Cross section of welded plate and melt pool by finite element model

Table 4. Results of out of plane displacement by experiment and finite element model

\begin{tabular}{ccc}
\hline \multirow{2}{*}{ Case } & \multicolumn{2}{c}{ Out of plane displacement $(\mathrm{mm})$} \\
\cline { 2 - 3 } & Experiment & FEM \\
\hline MIG & 8.3 & 8.0 \\
MIG+TIG $(-40 \mathrm{~mm})$ & 3.1 & 1.7 \\
\hline
\end{tabular}

\section{Weld distortion mitigation}

A distance between the MIG welding torch and the TIG torch and heat input of the TIG heating are important parameters. The heat input was determined by the preliminary performed numerical analysis so as to keep the melting pool size small. A relationship between distances of the two torches was investigated by numerical models and experiments. The finite element analyses were performed by placing the heat source distances from $+60 \mathrm{~mm}$ to $-80 \mathrm{~mm}$. The positive value was defined the TIG torch travelling in front of the MIG welding torch. The results were shown in Figure 6. It was found that effect of the additional heating was sensitive to the distance of the additional heating position and $-40 \mathrm{~mm}$ was the optimised distance. Figure 7 shows transverse residual stresses through the skin plate by the numerical analysis. The $-40 \mathrm{~mm}$ additional heating made smaller transverse residual stress compared with $+60 \mathrm{~mm}$ case. It is considered that heat input by preceding MIG welding make high temperature field at plate bottom and this temperature field reduces plate bending stress and angular distortions. 


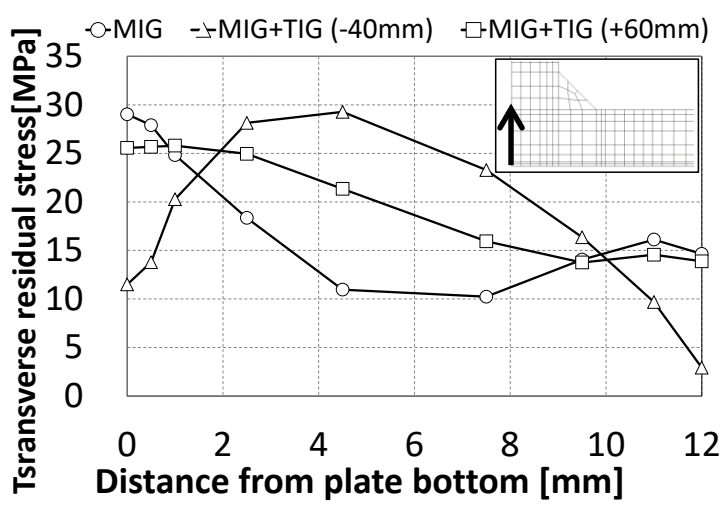

Figure 6. Relationship between TIG heating position and welding distortion

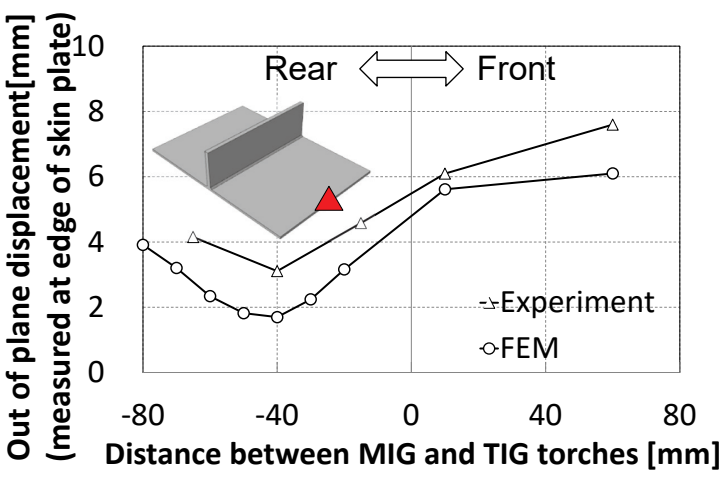

Figure 7. Comparison of transverse residual stress

\section{Conclusions}

In this study, welding distortion and its mitigation technique for fillet welding of aluminium plates were developed. The conclusions are summarized as follows.

(1) Finite element models of MIG welding, TIG heating and additional heating were developed and compared with experiments. Good agreement was obtained for MIG welding case. Larger melt pool was predicted by the finite element analysis. This difference was considered by absence of the weaving effect of TIG torch.

(2) Mitigation technique for fillet welding of aluminium plates was investigated by finite element models and experiments. The results showed that the optimised distance between the MIG welding and the TIG torch was $-40 \mathrm{~mm}$. An approximately $62 \%$ reduction was achieved by the proposed method.

(3) Additional heating behind a welding torch is more effective than the method proposed by reference [6] in our welding condition. This result indicates that the optimised heating condition is sensitive to weld sequences, heat input and plate thicknesses.

\section{References}

[1] R. Kamichika, T. Yada, A. Okamoto, Internal stresses in thick plates weld-overlaid with austenitic stainless steel (Report 2), Transactions of the Japan Welding Society, 5 (1974) 295302

[2] J. A. Goldak, M. Akhlaghi, Computational welding mechanics, Springer, 2005

[3] L. E. Lindgren, Computational welding mechanics, Woodhead publishing, 2007

[4] M.C. Smith, A.C. Smith, R. Wimpory, C. Ohms, A review of the NeT Task Group 1 residual stress measurement and analysis round robin on a single weld bead-on-plate specimen, International Journal of Pressure Vessels and Piping, 120-121 (2014) 93-140. http://dx.doi.org/10.1016/j.ijpvp.2014.05.002

[5] P. Michaleris, Minimization of welding distortion and buckling, Woodhead publishing, 2011. http://dx.doi.org/10.1533/9780857092908

[6] M. Mochizuki, M. Toyoda, Weld distortion control during welding process with reverse-side heating, Journal of Engineering Materials and Technology, 129 (2007) 265-270. http://dx.doi.org/10.1115/1.2400275

[7] S. Okano, M. Mochizuki, M. Toyoda, Thermal conductivity theoretical examination concerning characteristics of welding distortion produced by multiple heat source, Journal of the Japan welding society, 24 (2006) 324-330 (in Japnaese)

[8] S. Okano, M. Mochizuki, M. Toyoda, Study on angular distortion by temperature distribution control using back heating source, Journal of the Japan welding society, 25 (2007) 95-105 (in Japnaese)

[9] Simulia, Abaqus User's Manual, 2011 